\title{
La Medicina Legal en el Perú
}

LECCiON INAUGURAL DEL CURSO DE 1918.

\author{
POR EL DR. L. AVENDAÑo
}

Profesor de Clínica Médica y de Medicina Legal en la Facultad de Medicina

\author{
Señor Decano; \\ Señores Catedráticos; \\ Señores:
}

Hoy se inicia una nueva era en la enseñanza de la Medicina legal en la Facultad de Medicina de Lima. Merced a la munificencia del Gobierno, con el valiosocontingente aportado por la Facultad de Medicina, y con la dedicación y fructífera labor de la Cor.isión encargada de la construcción de este edificio (1), los estudiantes de la Escuela de San Fernando harán en adelante el aprendizaje de esta importante disciplina de las ciencias médicas, conforme a los adelantos efectuados en estas últimas décadas y con sujeción a las exigencias impuestas por la incesante trasformacion de las diversas ramas del derecho.

En este momento, en verdad solemne, que perdurará en los anales de nuestra Facultad y en la memoria de los concurrentes a esta significativa ceremonia, es deber primordial echar una mirada retrospectiva hácia el pasado, para justipreciar la marcha que ha: seguido la Medicina legal en el Perú y conocer a sus excelsos cultores; a los que tenemos obligación de ofrendar el homenage de nuestra gratitud, ya que ellos han sido los precursores en la fecun-

(1)-La Moroue, en cuyo recinto está el Aula da MBdicina legal. 
da labor que nos ha conducido al momento actual, en que henchidos de gozo y de patriotica satisfacción, vemos al fín cumplidos nuestros anhelos de dotar a la cátedra de Medicina legal de los elementos de estudio indispensables para llenar cumplidamente sus altos fines.

Ya en otra ocasion, y ha trascurrido de entonces más de un cuarto de siglo, cuando me opuse al concurso para ser adjunto titular de esta asignatura, me expresé así:

*Pocos son los datos que se poseén sobre la historia de la Medicina legal en el Perú, siendo muy posible que se la haya desconocido por completo en los primeros tiempos de la conquista; aseveración bien justificada si se reflexiona, que la Medicina legal ha adquirido el carácter científico que hoy tiene sólo en el trascurso del siglo $\mathrm{XIX}$; que el fanatismo y las preocupaciones profundamente arraigadas en la época del coloniaje, fueron siempre un poderoso obstáculo para el progreso de la ciencia en el Perú; y, que la enseñanza met6dica de la medicina recién se inicio a principios del siglo XIX, merced a los incesantes esfuerzos del sabio UNANUE*.

* Desde que se establecio el antiguo Tribunal del Protomedicato, erigido por célula de Felipe II, fechada en 11 de enero de 1570, la Real Audiencla y el Cabildo acudían a él en demanda de los consejos necesarios para resolver las cuestiones médico legales administrativas, civiles o criminales; siendo un hecho por demás sabido que la Real Audiencia, principalmente en el último tercio del siglo XVIII y en los albores del décimo nono, hacían reconocer a las embarazadas y parturientes por las comadres, y a los heridos por los cirujanos».

El Tribunal del Protomedicato continu6 como cuerpo consultivo de los poderes públicos, en asuntos médico legales hasta su extinción en 1851; reemplazándolo, primero la Junta directiva de Medicina creada en ese año, y después la Facultad de Medicina, que como se sabe se estableci6 definitivamente en setiembre de 1856. Las autoridades políticas y judiciales acostumbradas a ver en esta corporacion docente a la heredera del Protomedicato, en sus funciones administrativas, siguieron solicitando su concurso para ilustración de todas las cuestiones del resorte de la medicina pública, de la medicina social, fueran higiénicas o médico legales. Es bien conocido el valioso auxillo que la Facultad ha prestado siempre que han sobrevenido las grandes calamidades públicas, siendo bastante recordar su actuación cuando la guerra del 66 , cuando la epidemia del año 68, y, para no citar otras ocasiones cuando la guerra del 79. Hoy todavía, apesar de las innovaciones, 
realizadas, no obstante la difusión de los conocimientos de esta rama especial de la Medicina, y no embargante de existir una encumbrada corporación médica, reconocida oficialmente como cuerpo consultivo de las autoridades constituidas, el poder judicial acude siempre a la Facultad de Medicina en demanda de luces para orientarse en la resolución de los variados e importantes problemas de la medicina forense.

Mi querido discípulo y erudito comprofesor, el Dr Hermilo VALDIZAN, cuya meritoria labor en pró de la historia de la medicina pátria nunca será alabada lo bastante, ha tenido la gentileza de proporcionarme muchos y muy valiosos datos para reseñar lo que atañe a la evolución de la Medicina legal en el Perú.

En el Diario de Lima, que en el siglo XVII escribieron en esta ciudad los Mugaburu, se hace mención "de la frecuencia de la muerte súbita en la Lima colonial». Con tal motivo se discurre sobre la repeticion de dichas muertes, cuya causa se pudo a las veces indicar con visos de probabilidad, urefiriéndolas a trastornos cardio-vasales de múltiple manifestacionн; siendo en el mayor número de casos ignorada la causa del fallecimiento. Y como en aquellos remotos tiempos eran raros los médicos que practicaban la anatomía, la comprobación necropsica de tales muertes súbitas era cuestion azás difícil, por no decir imposible.

*No hubo, en la Lima colonial, un plazo reglamentario para las inhumaciones", dice Valdizan; y como comprobación de su acerto, refiere que los cadáveres de los frailes Francisco de Herrera, Mozquera y Pedro de Cordova fueion enterrados el mismo día de su fallecimiento.

En la misma época, es decir, en el siglo XVI, se practicaban los embalsamientos de los cadáveres de los virreyes y arzobispos, de preferencia. Los MUGabuRu dan algunos deţalles referentes al embalsamiento de los condes de Salvatierra, de Lemos y de Santistevan, del ilustrísimo Arzobispo de Lima Villagomez y de la Priora del Carmen Doña Juliana de la Madre de Dios. El Dr. TaFUR, umbrera dela medicina nacional en las postrimerías del siglo XVIII y principios del XIX, knos manifiesta que el embalsamiento de personajes en la Líma colonial se hallaba a cargo de los catedráticos de anatomía, de los cuales era privativa*. Entre los detalles que al respecto consigna el Dr. TAFUR, merece citarse que los mencionados catedráticos percibían un honorario de 500 pesos, amén de quedarles como beneficio las fuentes de plata necesarias para practicar la operación.

El Dr. Valdizan dedica un capítulo de su importante obra (aún inédita) Los Locos DE LA COLONIA, el IV que titula Las Sico- 
disgenesias.- Los pervertidos sexuales, al estudio de los delitos contra la honestidad, verdaderos ultrages públicos al pudor, que se cometían con inusitada frecuencia en la capital del virreinato en la época colonial.Si bien los hombres de ese entonces se preocupaban más que todo del fondo moral o religioso de estos hechos, es 10 cierto que también no dejaron de haber algunos que contemplaron el asunto de las inversiones sexudles y otros abusos genésicos, como muy serio y trascendental problema médico social.

Uno de los documentos más importantes relatîtvos a la Medicina legal en el Perú, correspondiente al siglo XVIII, es la obra publicada en 1781 por el R. P. Francisco Gonzales Laguna, titulada Zelo sacerdotal para con los niños no nacidos; en la que con notable erudición el autor se ocupa de la operación cesárea postmorten, kde los signos de la muerte en la difunta embarazada, del aborto y de algunas precauciones para evitarlo y, finalmente, de la acción de las sustancias abortivaso. Este opúsculo que comentó con recto criterio, en 1885 , mi querido y recordado compañero MANUEL Antonio MuñIz, constituye un notable estudio sobre varias e importantes cuestiones médico legales.

Como documentos médico legales producidos poco antes y después del establecimiento del Colegio de San Fernando, que como se sabe inicio sus labores en 1811 , colegio en cuyo plan de estudios no dí6 cabida UNANUE a la Medicina legal, voy a indicar someramente algunos de ellos, que entresaco de una nomina que me ha proporcionado el Dr. VALdizaN:

a)-Los cirujanos Juan de Palencia y Pedro Rodriguez, en 1802, informan como sigue:-- Después de concienzudo exámen, decimos: que Don Felipe Balcazar ha muerto por haberle faltado la respiración, sin la cual no puede tener curso la sangre y esto dimana de la fuerte compresión que el agresor 6 los agresores hicieron en su cuello, estrechando la trache arteria y el esofago hasta quitar el curso libre de la inspiración y expiracion, en cuyo operación hubieron de demorarse los agresores cuando menos de quince á veinte minutos para que parado el círculo parase la vitalidad. El caso lo acreditan los sintomas, en primer lugar, de las dilaceraciones situadas en los musculos laterales del cuello, y en segundo el color lívido de la cavidad animal, pues a estos cadáveres se les demora subitamente el círculo del líquido rojo, y con este motivo se trasluce á la cutícula el dicho colora. A pesar de los errores que hay en las líneas trascritas, es innegable que sus autores han revelado poseer conocimientos bien adelantadoś para su tiempo.

b) - En noviembre 23 de 1814, el Dr. Tafur, Protomédico, expidio un informe en dirimencia sobre la opinion de dos cirujanos 
de los que uno aseveraba ser mortales las heridas reconocidas en un cadáver, y el otro no las consideraba como letales.

c)-Julio 19 de 1815: informe sobre la paralisis de Don Manuel Palomera: en el quesu autor insiste sobre el buen estado de las facultades mentales del paciente y refuta el diagnóstico de paraplegia o parálisis parcial formulado por el médico asistente, concluyendo por suponer se haya tratado sólo de un reumatismo mal curado.

d)-Setiembre 1.0 de 1815-El Protomédico Dr. TAFur informa haber visto en consulta con VERGARA y D. JOSE SEguin a doña Rosa Marisso en el convento de las Descalzas. "Es un delirio melancólico que ha trastornado tanto su celebro que solo una larga continuada curación podrá restituirlo al estado de combinar con orden las ideas; pero expuesta entretanto á que las repetidas convulsiones que la asaltan afecten alguna viscera de modo que termine su vida y sea víctima no de la enfermedad primaria sino de las resultas. siempre funestas que tienen cuando son fuertes y frecuentes los insultos convulsivos". No sería este un caso de histeria?.

e)-Octubre 13 de 1815-Informe tal vez en dirimencia a los de los doctores Villalobos y Devoti, sobre el estado de la salud del Dr. Miguel de Eyzaguirre, en el que aprueba el régimen a que se halla sujeto el enfermo, después de suponer que el sujeto tiene una concreción poliposa en el pecho, capaz de ocasionar una muerte súbita.

f)- En 16 de enero de 1816, el Dr. Miguel Tafur, informa sobre el estado mental de D. Domingo Alcaras, cuyo diagnóstico de su vesanía discute, calificándolo como maniaco furioso; hace mucho incapié sobre la necesidad de atenderlo en la loquería de San Andres, diciendo que el Hospital de San Pedro (hospital de clérigos) es una casa inadecuada para tal asistencia. TAFUR desde esa época, reclamaba asistencia especial para los trastornos de la mente en establecimientos ad hoc.

g)-Entre noviembre 12 y diciembre 16, sin fecha-Dictamen sobre la conveniencia de establecer en el Callao una Junta de Sanidad, tal como la hay en todos los puertos de Europa y la hubo en tiempos pasados en esta capital, que precava de todo contagio a la ciudad.

h) - 16 de diciembre de 1816-Informe del Protomedicato al Virrey sobre la fiebre amarilla de Panamá, en el que se pronuncia por la interdicción de las personas y de los objetos materiales, indicando como medidas de saneamiento: la exposición de las telas al aire y al sol por 256 más días, y colocacion de los objetos en cuartos en los que se haya quemado azufre y salitre 6 polvora.

i) -El 11 de febrero de 1817, el Protomédico general Dr. Mi- 
GUEL TAFUR, informa sobre el honorario que debía pagarse por un embalsamiento: informe en el que después de exponer lo que he dicho antes, sobre el privilegio de los catedráticos de anatomía y sobre los honorarios y demás provechos que correspondían a los ejecutantes, insiste que el trabajo debe avaluarse teniendo en consideración las circunstancias y carácter que tenía el difunto; y como quiera que en el caso particular el cirujano tuvo que abandonar su trabajo y hacer un viaje de mas de doce leguas, concluye por que se le paguen los 500 pesos que cobra y se le den además 200 pesos como indemnización por el viaje.

Este documento parece de la épcoca presente, pues son los mismos argumentos de orden moral, los que aduce TAFUR y los que norman hoy la conducta de los peritos en esta materia.

j)-Informe firmado por los doctores JOSE MARIA Falcon y Jose Manuel Valdez, fechado en abril 9 de 1817 , y que se refiere a una herida por arma de fuego que intereso el muslo izquierdo de Don Manuel Barrañao.

k)-Informe del Dr. TafuR, su fecha junio 30 del mismo año, emitido en la causa seguida a José de la Cruz, por homicidio en la persona de Manuela Medrano Sánchez. Describe las contusiones que recibiera la occisa (pedradas) radicadas ssobre el celebro, y con el mismo y con repetición los últimos sobre el cerebelo (vulgo, la nuca) orígen del principio vital y sobre los pulmoness; insiste sobre la textura delicada e importantísimas funciones de ostas visceras y concluye por que los golpes fueron de necesidad mortal.

1)-Con fecha 10 de setiembre de 1817 , el Dr. Miguel Tafur, actuando como Protomédico, comenta el reconocimiento hecho por el cirujano Utrilla en el cadáver de Tomasa Arredondo, quien, sin haber practicado la diseccion indispensable en estos reconocimientos, aseguró que la herida fué de necesidad mortal porque atravez 6 la cavidad del pecho y rompió la arteria magna o aorta. TAFUR considera reprensible tanta lijeresa, e insiste sobre el hecho de que en el supuesto de haberse herido el tronco de la aorta, la muerte habría sido inmediata, sin dar tiempo a que se le administraran al herido los auxilios espirituales, como en efecto le fueron administrados. Después de otras consideraciones, y suponiendo comprometidos otros órganos, dice que la adesgracia se habría cortado en la mano diestra y pronta de un cirujano inteligented.

El informe que comento revela en su autor muy recto criterio y notables conocimientos médico legales, pudiendo hoy mismo figurar como un dictamen ajustado a las enseñanzas de la ciencia.

Hi)-En octubre 29 del mismo año, el Protomédico Dr. Tafur, emite un informe de estimación (una tasación) con motívo del re- 
clamo que sobre la entidad de sus honorarios hicieron los profesores VASQUEz y LizaRRaga. En apoyo de sus conclusiones hace la historia de varios casos parecidos.

m)--Enero 12 de 1819-Informe del Dr. TAFUR. "La herida de que muri6 José Noguera fue de necesidad mortal por que habiendo pe netrado la cavidad del vientre, solo lo dexo con vida el tiempo que gastó en andar las 667 varas que median entre el sitio en que fue herido y en el que murio sin dar lugar para que se le auxiliase espiritual ni corporalmente. Si se hubiese hecho la visección del cadaber se habría visto si la ruptura de la arteria Aorta o de las del riñon o del bazo motibaron tan pronto el fallecimiento. El haver escusado esta diligencia es el motivo por que los cirujanos UTRILLA y POMPEYO no clasificaran como debieran las heridas; 10 habrían hecho así sin duda si se les hubiera advertido la celeridad con que muri6 Noguera y que el cadaber estaba traspasado, y no se habrían limitado á solo la herida anterior del vientre clasificándola por tanto como simple y atribuyendo la muerte á un derrame que hubiera impedido el auxilio oportuno. La falta de estas advertencias disculpa su yerro, y para que en lo sucesivo no haya reconocimientos con tanta precipitación ya los ha hecho comparecer este Tribunal para advertirles la exactitud y esc rupulosidad con que se deben hacer los reconocimientos, diligencia que se extenderá a los cirujanos en particular".

Los documentos de cuyo contenido he hecho una rápida sinopsis, son por demás importantes: revelan que el Dr. TAFUR dominaba por completo las disciplinas médico legales, pues ya informaba sobre cuestiones de orden médico como de orden quirúrgico, ya emitía su opinion en asuntos administrativos como en los contenciosos sobre honorarios, y, finalmente, ejercía sus augustas funciones de protomédico, encarrilando a los profesionales de esa época a rue ejercieran su ministerio con sujección a las reglas de la moral y los preceptos de la ciencia.! Cuán conveniente sería que hubiera hoy un Dr. TAFUR, que enmendara tanto desacierto que a diario se comete por los doctos tratándose de asuntos médico legales!.

He dicho ya que en el antiguo Colegio de San Fernando, no hubo nada en la enseñanza que tuviera relación con la Medicina legal; $y$, en verdad que después de conocidos los documentos debidos al talento y competencia de TAFUR, extraña que UNANUE no hubiera. aprovechado de tan buen maestro para difundir los conocimientos médico legales. En medio de las viscicitudes por que atravezó el Colegio, ya relatadas en otra solemnidad, y que en varias ocasiones determinaron su completa paralización, nada se hizo en lo que atane a la fundación de la asignatura de Medicina legal; pues las dispo- 
siciones que se dictaron al respecto, y que indicó en seguida, lo fue ron directamente por el Gobierno sin intervención del personal del Colegio.

En efecto, por decreto de 6 de marzo de 1835, se dispuso:- "Los profesores de medicina y cirugía de los hospitales están obligados á dar lecciones de Clínica a los practicantes, especialmente en los casos de reconocimiento de heridas, y demás asuntos médico legales". Esto es ya un bosquejo de enseñanza de la Medicina legal, que ignoro si se llevaría a la practica: Es menester llegar al 4 de marzo de 1843, en que debido a los incesantes esfuerzos de Cayetano HereDIA se reorganiz6 definitivamente el Colegio, para que la Medicina legal figurara en el plan de estudios.

En el decreto de reorganización de ese plantel, expedido como queda dicho en 4 de marzo de 1843, en el Art. $2 .^{\circ}$ del Título 4. ${ }^{\circ}$, se dispuso:- Habrá nueve profesores que enseñarán:-Química;* Historia Natural;-Anatomía general, descriptiva y patologica; - Fisiología e Higiene;-Patología y Terapéutica generales;- Materia Médica, Arte de formular y Medicina legal,-Institucio- nes quirúrgicas;-Clínica interna y Nosografía médica;-y, Clíni- ca externa, Anatomía topográfica y Obstetrician. Y en el título 80 "De los profesores y del modo de enseñar", en el incíso 13 del Art. - 2.0, se ordena:- un el estudio de la medicina legal, no deberá limi - tarse a la parte forense sino que manifestará la influencia que la me- dicina puede tener en la legislación y politica de los pueblos."

Asombra la clarovidencia de Heredia que, superhombre como fué para trabajar sin descanso por el progreso de la medicina pátria, nos habla de la influencia de la medicina en la legislacion y política de los pueblos, en una época en que la medicina social sólo podía existir en la mente de los hombres privilegiados como él!!. Cuantos años han trascurrido para que se cumpla la profecía de HERELIA, pues, sin que se me tache de exagerado, puedo decir que es. a los intelectuales del ultimo cuarto del siglo decimonono y a los. de la presente centuria, a quienes corresponde haber incorporado estas disciplinas en el acervo general de los conocimientos humanos.

Pero era natural que así se expresara, quien produjo documentos médico legales como los dos que trascribo a continuacion; informes sóbrios precisos y de verdadero corte académico:

"República Peruana-Colegio de la Independencia-Lima, á 25 de Agosto de 1845-Sr. Intendente de Policía- Ayer, á la una del día se practicó el reconocimiento del cadáver de la morena Carmen, y del individuo llamado Avelino. La primera murio á consecuencia de una dilatación aneurismática del corazon y aorta y de una afección crónica del cerebro; y el segundo por una ruptura do 
un tumor aneurismático de la aorta descendente, formado en el sjtio en que esta arteria pasa del pecho al vientre. Estas muertes no tienen nada de notable, pues á la mujer se le había pronosticado pocos días antes por uno de los profesores que asistió á la autopsia, que moriría repentinamente, si no arreglaba su género de vida y el hombre acorto su existencia por haberse excedido en los alimentos y tal vez en licores espirituosos, como se deduce del estado en que se encontro el estómago y duodeno.

Determinadas, pues, las causas de estas muertes, como lo han sido también las de las anteriores, si exceptuamos al moreno Pablo, debe cesar la alarma que hayan podido ocasionar tales desgracias, que según se ha observado se repiten todos los años al aproximarse la primavera.

\section{Dios guarde a U.S. \\ (firmado) Cayetano Heredia}

Protomedicato General.

Sr. Intendente de Policía.

Lima, 24 de Agosto de 1845.

En el cadáver de Josefa Caso, que el teniente del distrito 1.0 remiti6 al Anfiteatro la noche última, se han encontrado alteraciones profundas, principalmente en el cerebro, pulmones, corazbn, intestinos y útero que manifiestan hasta la evidencia el estado de enfermedad crónica en que se encontraba; y si es cierto que murió repentinamente, solo se puede explicar su muerte por la alteracion de los pulmones que se hallaban fuertemente hiperemiados, llenos de sangre, pues los otros al fin la habían llevado á la tumba, pero de un modo lento.

\section{Dios guarde a S.U. S. (firmado) Cayetano Heredia}

El 13 de marzo del mismo año fué nombrado profesor de $\mathrm{Ma}$ teria Médica, Arte de formular y Medicina legal, el Dr. JuAN VASquez Solis, que fué el primer maestro que dictó en la Escuela de Medicina las lecciones correspondientes a esta importante rama de los conocimientos médicos.

El Dr. Valdizan en su obra La Facultad de Medicina de Lima, dice lo siguiente al hacer la biografía de los ilustres varones que acompañaron al Dr. Heredia en su labor de organización de la enseñanza médica en el Perú:

*El doctor JuAN VASQuez Solis, había sido incorporado a la Universidad de San Marcos en doce de mayo de 1833. Profesional distinguido, desempeño el rectorado de la Universidad y fué con- 
siderado por el llustre Colegio do Abogados en el número de sus miembros.

«El Doctor VAsquez Solis reunía a una gran habilidad profesional una excepcional cultura científica.

"En febrero de 1814, fué propuesto por la Junta Gubernativa del Colegio de la Independencia como sustituto del Doctor MARCelino Aranda en la Cátedra de Higiene, pero el mal estado de su salud le obligo a renunciar el cargo, que fué adjudicado al Doctor Manuel Damaso Herreran.

Como se vé el Dr. Vasquez Solis fué una importante personalidad, versada tanto en asuntos médicos como jurídicos, como lo prueba el hecho de haberle abierto sus puertas el Ilustre Colegio de Abogados; $y$, su preparación en asuntos de la Medicina pública fue reconocida por Heredia que quizo hacerlo primero profesor de Higiene, y que al fin consiguió que lo fuera de Medicina legal. Desgraciadamente el estado precario de su salud, que lo oblig6 a no aceptar la Cátedra de Higiene, parece no le permitió desplegar todas sus aptitudes al frente de la clase de Medicina legal.

HEREDIA no se conform6 con reorganizar el antiguo Colegio de la Independencia: aspiraba algo más, quería transformar al Colegio en una verdadera Facultad de Medicina; y, sí bien sus aspiraciones demoraron algo, al fin vio coronados sus anhelos en la reforma llevada a cabo el 7 de abril de 1855 , en la que se reconoci6 como curso independiente el Medicina legal y Moral médica. Reformada por completo la Universidad de San Marcos y establecidas definitiva mente las cinco facultades de Teología, Jurisprudencia, Medicina, Ciencias y Letras se dictó por el Poder Ejecutivo, el 9 de setiembre de 1856, el Reglamento de la Escuela de Medicina en el que entre las cátedras correspondientes a la Facultad figura la de Medicina legal y Toxicología, que desde esa época tiene la existencia que conserva hasta el día.

Fué designado como catedrático de este curso, en la misma fecha el Dr. JOSEJ ULIAN BRAvo, cuya brillante actuación tanto en la enseñanza en el Colegio de la Independencia como en la práctica civil, es bien conocida, puesto que su nombre ha perdurado en la memoria del públíco entre los más prestígiosos profesionales que han ejercidoen Lima.

El Dr. Bravo resigno el cargo que le confirió el Gobierno, y éntonces fué nombrado en $1^{\circ}$. de octubre de $1856 \mathrm{el}$ Dr. Mariano Arosemena Quezada que había sido designado entre los fundadores de la Facultad, como catedrático de Anatomía general y Patológica.

El Dr. Arosemena Quezada, nacido en Panamá y que feciblo 
el diploma de médico a la temprana edad de 19 años, dictó el curso sin interrupción alguna, durante 26 años hasta 1882 , en jue víctima de una hemorragia cerebral, qued6 invalidado por completo para el ejercicio del magisterio. Ya en otra ocasión me cupo la oportunidad de hacer el elogio necrológico de este sabio maestro, que vislumbr6 en 1868 la existencia de un gérmen animado como agente patógeno de la fiebre amarilla; por lo que me limitaré en este instante a declarar, que a pesar de la carencia de elementos materiales, supo inspirar en sus alumnos el entusiasmo por el cultivo de esta ciencia;que arregló un pequeño tratado de indiscutible utilidad, que circul6 manuscrito entre sus discípulos; y, que cuando las exigencias lo reclamaban solía hacer ejercicios prácticos a fin de establecer coordinacion entre los hechos consignados en los autos que estudiaba y los principios de la ciencia y las reglas del arte. Recuerdo que cuando yo era estudiante de anatomía, fué al Anfiteatro a disparar con arma de fuego sobre un cadáver, para establecer la relación existente entre la forma del disparo y la distancia a que se le hacía; queriendo así ilustrarse para informar en un asunto muy delicado sometido a su estudio. No me fué dado escucharle en la cátedra, pues cuando fuí alumno del curso de Medicina legal, yacía ya inválido en el lecho del dolor; pero en 1884, cuandola suerte me depar6 dilucidar lo relativo a la Responsabilidad del médico en el ejercicio de su profesión. como tema para optar el grado de licenciado, entonces acudí al inteligente y venerable maestro que con la mejor buena voluntad, con inagotable cariño y con inmenso caudal de ciencia me ilustró sobre el punto, me di6 sabios y oportunos consejos y me relató dos casos prácticos que están consignados en mi tésis. Me retiré del domicilio del Dr. Arosemena Quezada, con el ánimo angustiado al contemplar a ese portentoso cerebro, ya lesionado por cruel dolencia, conservar su integridad intelectual que no podía desplegar como antaño, por la impotencia física de los organos do la locomocion.

Durante el profesorado del Dr. ARosemena Quezada, surgieron muchos obreros laboriosos e inteligentes, que utilizaron de los conocimientos médico-legales propagados entonces; y, como prueba del provecho obtenido existen en los archivos de nuestros tribunales, y en las columnas de la prensa cientifica y política, documentos médico legales que de seguro no desdeñarían suscribir las verdaderas eminencias de la ciencia. Como ejemplo citaré el informe suscrito por los doctores Antonio Evaristo D'Ornellas, Jose Casimiro Ulzoa (que se especializó en Medicina Legal, durante su permanencia en Europa), Mariano Arosemena Quezada, Manuel Odriozola, Rafael Grau, Jose, Jacinto Corpancho y Archi- 


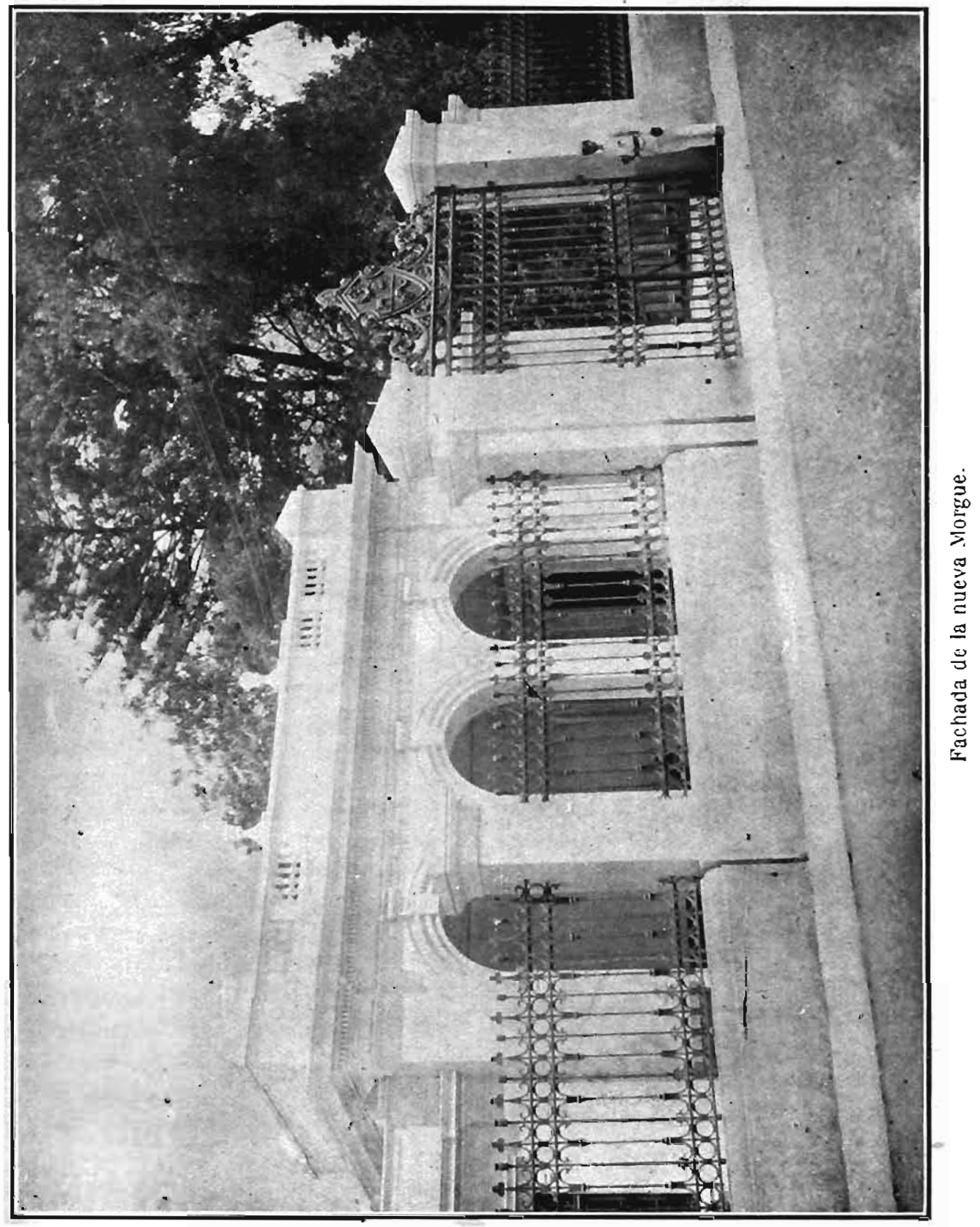


Baldo Smith, con mötivo del suicidio del señor IRARRAzabal ministro de Chile, acaecido en Chorrillos el 15 de octubre de 1859 notable informe que constituye una prueba del adelanto de la Medicicina legal, en el país, en esa época. Contemporáneos y colaboradores del Dr. Arosemena Quezada en la labor médico legal fueron los doctores LeONARDo VilLaR y MaNuel AdOLFo OlaEchea, cuya competencia como médicos legistás no necesito poner en relieve ya que ha sido universalmente conocida. Y han sido o los son aún, cultores de esta importante discíplina de las ciencias médicas, entre otros varios, los siguientes:-como jurisconsultos, los Doctores Manuel A. Fuentes, autor de un Manual de Medicina legal y que dicto el curso de Medicina legal en la Facultad de Jurisprudencia, durante el corto tiempo que figuró en el plan de estudios; Francisco M. FerNANDEz, cuya competencia fué generalmente conocida; Miguel A. DE LA LAMA, autor del Diccionario de Jurisprudencia y de Legislacibn Peruana, notable obra en que se patentizan sus grandes conocimientos médico legales, de la adaptación del texto de Filippi a la legislación peruana, y director por muchos años de $₫ E l$ Derechon, en que se han publicado notables estudios médico forenses; Jose V. Arias, autor de los Comentarios al Código Penal peruano; Paulino Fuentes Castro, el incansable fundador y sostenedor de "El Diario Judicial", prestigiosa revista en que se han estudiado y comentado muy trasceddentales cuestiones médico legales; JOSE TORIBio Flores, que publicb un Tratado de Medicina legal; Oscar Miro Quezada, que hoy dicta en la Facultad de Jurisprudencia, el curso de Antropología criminal; Julian GurLlermo Ronero, colaborador de «El Monitor Médico»; \&.;-y, como médicos además de los Doctores Villar y Olaechea, ya citatados, los Doctores J OSE A. DE los Rios, Manuel C. Barrios, Manuel A. Muñiz, David Matto, Tomas Salazar, Jose Casimiro Ulloa, Pablo Patron, Manuel A. Velasquez, ignacio la Puente, Guillermo Olano, Wenceslao Salazar, Carlos E. Paz Soldan, Guillermo Fernaindez Davila, Leoncio Pajuelo y los alienistas Hermilio Valdizan, E. Pardo Figueroa, Wenceslao mayorga, B. Caravedo Prado, S. Lorente, honorio Delgado, Carlos Bambaren, \&.

Después del fallecimiento del Dr. Arosemena Quezada, acaecido en 1885, fué designado como catedrático principal interino de medicina legal y Toxicología, a principios de 1886, el Dr. Manuel C. BARrios, quien obtuvo la propiedad de la cátedra en concurso celebrado en enero de 1889, habiéndola desempeñado, con algunas interrupciones, hasta diciembre de 1913 , en que obtuvo şu jubila- 
cion. No ha llegado todavía el momento de juzgar la labor realizado por el Dr. Barrios en la cátedra de Medicina legal, por lo que me limitaré a decir:-que en el programa presentado al concurso en referencia, indicó la necesidad de crear un Instituto de Medicina legal, expresándose al respecto la Comisión de la Facultad que juzgo el programa, en los términos siguientes:- «Es el último el tratado con que termina el citado razonamiento (el del programa), destinado á revelar las ideas del autor sobre la manera como debe enseñarse en nuestra Escuela las asignaturas que la Cátedra en concurso comprende. En él se indican la necesidad y ventajas de establecer un Instituto de Medicina legal y Toxicología en el que pueda hacerse la enseñanza práctica del curso, y al cual estaría anexo un Necroscopio (Morgue) destinado como los de su género, á la exposición de cadáveres encontrados por la policía, á las autopsias de oficio y demás investigaciones médico-legales: establecimiento que prestaría inmensos servicios no tan sólo á la Escuela sino también y muy especialmente á la policía y á la justicia criminal, y que contribuiría á formar peritos médico-legistas de que tanta necesidad tiene todo Estado bien organizadon; - que ha sido obra suya la creación del Laboratorio de Toxicología, dependencia de la Facultad, que ha prestado y presta muy buenos servicios, tanto á los estudiantes del curso,como al poder judicial; $y,-$ que desde que tomo posesión de la asignatura, hizo cuanto le fué posible para efectuar enseñanza verdaderamente práctica. Al efecto consiguio que la Facultad acordara, que el profesor de Medicina legal integrara la comision administradora del Anfiteatro Anatómico, y que fuera obligatoria la asistencia de los alumnos del curso a las autopsias médico legales. Desgraciadamente estas disposiciones no pasaron de la categoría de buenos deseos, y la enseñanza práctica de la Medicina legal se ha limitado hasta hace pocos años, a la reducida labor realizadable en el Laboratorio de Toxicología.

Cuanto al peritage oficial, es decir,el que se ejerce ante el poder judicial en las causas criminales de oficio, después de la supresión del Protomedicato, se dispuso que los segundos médicos de los hospitales fueran los obligados a desempeñar tal cargo. Pero posteriormente, por decreto de 27 de febrero de 1852, se preceptuo:- «Los reconocimientos y la expedición de certificados, encomendados a los segundos médicos de los hospitales, deben hacerse en adelante por todos los cirujanos del ejército que se hallen en la capital, y disfruten sueldo; turnándose en este servicio en el orden del rol que se formarán.

Después y casi contemporáneo con la creación de la cátẹdra 
de Medicina legal, fué el establecimiento de los médicos de policía (establecimiento ratificado en el Reglamento de moralidad pública y de policía correccional, promulgado el 31 de diciembre de 1873), encargados de practicar los reconocimientos y expedir los informes necesarios para la buena marcha de la policía judicial. Esta reforma puede considerarse como el principio del estudio práctico de la Medicina legal, pues es sabido que en todas las grandes poblaciones los depósitos de la policía son los que proporcionan el mayor contingente para ello. Y fué como médicos de policía que lucieron su competencia Arosemena Quezada, Leonardo Villar, Manuel Adolfo Olaechea, David Matto, Tomas Salazar, Manuel C. Barrios, Ignacio la Puente, Wenceslao salazar y varios otros.

Como adelantos realizados en el Perú, que tengan relación con la enseñanza y práctica de la Medicina legal, merecen mencionarse;-la nueva organización dada al servicio médico de la policía, con la erección de la Morgue para el reconocimiento de los cadáveres, y la creación del servicio de identificación dactiloscópico y fotográfico;-la completa organización de los Registros del Estado Civil en todos los Concejos Municipales de la República;-la creacion de un Laboratorio municipal de química (hoy dependencia del Instituto Municipal de Higiene), cuyo jefe era en los primitivos tiempos consultado como perito en todas las cuestiones que se refieren a la Toxicología;-la fundación de la Academia Nacional de Medicina, cuerpo consultivo de los poderes públicos, llamada a ilustrarlos en todas las cuestiones que son del resorte de la medicina, principalmente de la medicina social. Los Tribunales de Justicia comprendiendo los altos fines que competen a esta docta corporación, le piden su informe, en última instancia, en todos los asuntos médico legales; - la instalación del Laboratorio de Toxicología en nuestra Facultad, dependencia que dispone de todo lo necesario para la enseñanza de la especialidad y que ha prestado ya muy buenos servicios a la administración de justicia;-la creación de la Cátedra de Enfermedades mentales y nerviosas en la Facultad de Medicina, recién provista en 1916, cuyas enseñanzas han de servir en grado máximo para la cultura especializada de los futuros profesionales:- - la inauguración del manicomio de la Magdalena, asilo colonia del sistema Open-door, que ya debía estar bautizado con el nombre de "Hospicio Ulloa", para perpetuar la memoria del sabio maestro que inició entre nosotros el tratamiento científico de la enagenación mental: asilo en que ha de funcionar la Clínica de enfermedades mentales y nerviosas; - y, finalmente, la edificación y organización de esta repartición, que con las dos antes mencjo- 
nadas constituyen bien poderosos elementos para difundir entre los intelectuales médicos y juristas las sabias y proficuas enseñanzas de la ciencia médico legal.

Pero lo relativo a la Morgue merece parrafo aparte.

En el mismo año da 1889 en el Dr. Barrios, como ya lo dicho, indicara la necesidad de establer la Morgue (como dependencia del Instituto de Medicina legal), un ilustrado funcionario judicial, el Dr. Emiliano Carvallo, iuez del crimen de Lima, se dirigí a la naciente Academia Nacional de Medicina haciéndole ver la urgencia de fundar un establecimiento ad hoc, que sirviera para las múltiples e importantes funciones que competen a la Morgue. La Academia acogí como se debía tan feliz iniciativa, y manifesto su aprobación a la labor del competente juez, enviándole una honrosísima comunicación.

Dos años después, y como resultado de los trabajos hechos por el entonces teniente coronel Pedro E, Muñiz, Sub-prefecto e intendente de Lima, se expidio un supremo decreto creando la Morgue: dependencia de la sub-prefectura de Lima, destinada al reconocimiento e identificación de los cadáveres: importantes operaciones que antes se efectuaban en una sala del Cementerio General, carente de todas las condiciones materiales exigibles para poder ejecutar correctamente una autopsia médico legal. Como el Gobierno no se encontraba en aquella época en aptitud de hacer el fuerte gasto que demandaba la construcción de un edificio ad hoc, se limit6 a solicitar de la Facultad de Medicina la cesion temporal de una de las salas del Anfiteatro anatómico, en la que se colocaron: una tarima, algunas perchas y una mesa de autopsias, que hasta hoy se conserva y que es la que nos servirá en esta aula para los trabajos practicos de tanatología.

El 17 de julio de 1891 se formul6 un proyecto de Reglamento para la Morgue, por una comisión compuesta por el Coronel A. D. Zapatel, prefecto de Lima, Dr. S. G. Paredes, presidente de la Corte Superior y Dr. L. Villar, decano de la Facultad de Medicina y Médico de policía. En el Reglamento se dispuso que: la administración de la Morgue-erigida provisionalmente en un salón del Anfiteatro de Anatomía de la Facultad de Medicina-dependía inmediatamente del Intendente de Policía de Lima:-que los mé dicos de policía eran los peritos del establecimiento, con exclusion de cualquier otro; - que en los casos en que el reconocimiento de los cadáveres fuera útil al estudio práctico de la Medicina legal hecha en la Facultad de Medicina, los médicos de policía debían proporcionar al Catedrático de dicha asignatura y a sus discípulos, todas 


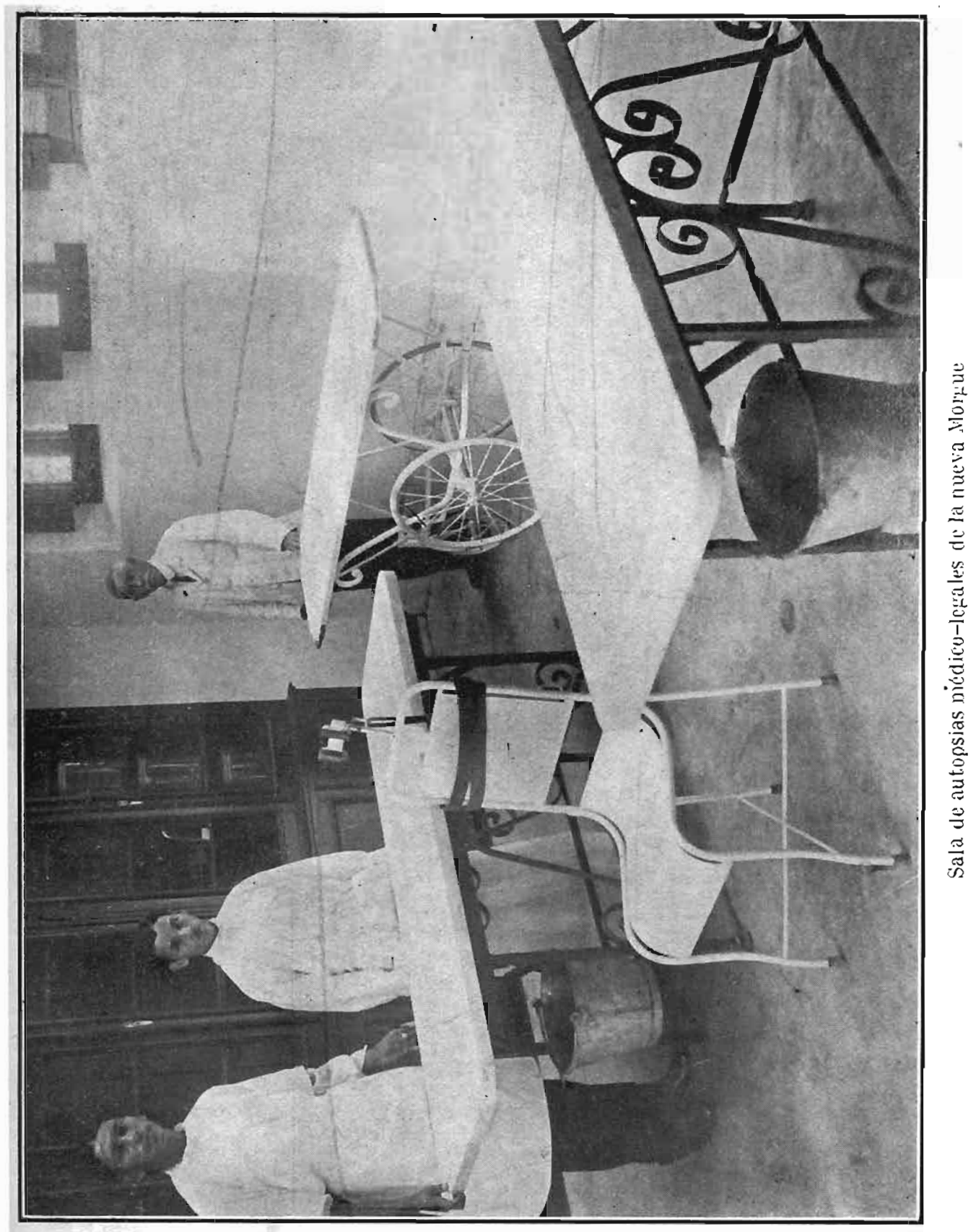


las facilidades necesarias para la practica de las investigaciones convenientes:-y, entre otras disposiciones de menor entidad, se ordenaba el nombramiento de un sblo empleado con el título de conserje. Muy pocas veces, los señores médicos de policía cumplieron la prescripción de este reglamento en lo relativo al estudio practico de la Medicina legal, hecho que no tienenada de sorprendente, desde que faltaba lo principal, la ingerencia directa del catedrático del curso en las labores de la Morgue.

No he de relatar con todos sus detalles las viscisitudes de la Morgue que con tan sana intención fundó el General Muñiz. Faltándole a la oficina los recursos materiales para su independiente y completa instalacion, y para su correcto funcionamiento, se ví6 obligada la sub-prefectura a abandonar el local ante las reiteradas peticiones de la Facultad de Medicina, que lo reclamb en varias ocasiones por exigirlo así las necesidades del anfiteatro y el aumento creciente en el número de los alumnos de los cursos de anatomía. En tan crítica situación hubo que colocar los escasos enseres de la titulada Morgue, en un cuartucho adosado a la reja del Jardín Botánico por el lado de la Calle de Cangallo: tabuco inadecuado para el fín a que se le destin6, y que por muchos años ha sido un terrible foco de infección para todo el vecindario.

Data de antiguo la preocupación de las autoridades políticas, de los médicos de policía de Lima y de los gobiernos, de edificar un local ad hoc para el funcionamiento de la Morgue; intensificándose la actividad en este sentido cada vez que la Facultad ha reclamado la devolución de la sala, que ha servido para la labor policial.

Las primeras tentativas al respecto se hicieron en 1897 , en que, con motivo del primer reclamo que hiciera la Facultad de Medicina se expidió por el Gobierno, siendo ministro del ramo el Sr. Lorenzo Arrieta, la suprema resolución de 29 de abril de ese año, en la que previos los considerandos del caso, se resolvió nombrar «una Comisión compuesta de tres médicos, que serán los dos de policía (Drs. Villar y Tomas Salazar) y el Dr. Miguel Colunga, y de los ingenieros D. Felipe Arancibia y D. Alejandro Guevara, para que procedan a escojer, inmediatamente, el sitio conveniente y determinar las condiciones técnicas que debe tener el edificio destinado a la Morguen. Esta Comisión, como era de esperarse dada la indiscutible competencia de sus miembros, se expidió brillantemente en un informe fechado en 15 de mayo del mismo año, en el que se señala como mejor ubicación para la Morgue el terreno de propiedad municipal situado en el término de la Alameda del Tajamar; e indicando las particularidades a que debía sujetarse la construcción, entre cuyas secciones se menciona: "Una Sala de congelación". El Go- 
bierno, en vista de este informe, ordenó que por el Ministerio de Fomento se designara a un Ingeniero de Estado para que levantara el plano respectivo y formara el presupuesto de la obra; designación que recayó en el Doctor Santiago Basurco, quien en 5 de enero de 1898 presentó los planos y todas las especificaciones relativas al encargo que se le hiciera, sujetándose a las indicaciones hechas por la Comisión especial. En el estudio del Doctor Basurco se incluye la sala de congelación, perose prescinde en lo absoluto de la posible utilizaación del edificio para la practica y enseñanza de la Medicina legal. El proyecto del Dr. Basurco fué considerado como muy vasto y de costosa ejecución, por lo qué en resolución ministerial (de Fomento) de 18 del mismo enero, se le ordenó revisara su estudio y presupuesto limitándolo" a las necesidades que demanda la Capital en relación con los servicios que debe prestar un establecimiento de esta clase». El Dr. Basurco dió cuenta de este cometido el 31 del ya citado enero, acompañando el nuevo proyecto reducidoen extensión y en costo, en el que entre otras supresiones se prescinde de la sala de congelación. Los dos estudios del Dr. Basurco no pasaron de la esfera de proyectos.

En 1905 insiste la Facultad en la desocupación de su local, y vuelve a ponerse en trámite la construcción de la Morgue, o su instalación provisional fuera del recinto del Anfiteatro; pero, a pesar de los esfuerzos hechos por la Prefectura del departamento, no se llega a tomar un acuerdo definitivo, no obstante de que continúan los reclamos de la Facultad en el trascurso de 1906.

A fines de este año, en 28 de diciembre, la Prefectura del departamento, absolviendo el informe que se le pidiera sobre la posibilidad de utilizar el final de la Alameda Grec para la ubicacion de la Morgue, eleva a la Dirección de Gobierno el proyecto arreglado por el arquitecto Sr. Robert, al servicio del Estado. En dicho proyecto, de muy buena apariencia aunque incompleto, no había sitio reservado para la clase de Medicina Legal, ni se consideraba la instalación de un frigorífico. El estudio del Sr. Robert no fué tomado en consideración, y sirvió únicamente para aumentar en algunas fojas el axpediente de la materia

En setiembre 2 de 1912 durante el Gobierno del Sr. Billingursht, con motivo de la próxima reunión del $\mathrm{V}$ Congreso Médico Latino Americano,el Sr. Decano de la Facultad de Medicina volvib a insistir sobre la desocupación del salón del Anfiteatro temporalmente cedido para la.Morgue, en el que la Facultad había resuelto instalar el Museo de Anatomía descriptiva. Con tal motivo la sub-prefectura de Lima elev6 a conocimiento de las autoridades superiores da po- 
C. - el plano y los presupuestos formulados por el Ingeniero Sr. E. Diez Canseco: plano en el que se dí cabida a un Anfiteatro para la cátedra de Medicina Legal, y que aunque muy bien concebido, of recía el vacío de la falta de un frigorífico, dependencia indispensable en establecimientos de este género. Entonces, y por indicación del Sr. Billingursht, se hicieron algunas insinuaciones a la Facultad de Medicina para que cediera el terreno necesario para la edificacion. La Facultad accedí a la demanda, y acord6 ceder, en el local de su propiedad, el area de terreno que se creyera bastante para el nuevo edificio.

El proyecto del Sr. Diez Canseco, que se consideró como de muy muy elevado costo, fué reducido y modificado por el ingeniero Sr. Martinez conservándose al Anfiteatro para la cátedra de Medicina legal, y con prescindencia del frigorífico; y aunque informaron favorablemente en el asunto las direcciones de fomento y salubridad, y no obstante la decidida voluntad del Sr. Billingursht, las evoluciones políticas sobrevinientes impidieron que la obra se llevara a término.

Finalmente, el Dr. José Pardo, en el primer año de su gobierno, en 1915, consigno en el proyecto de Presupuesto General presentado a las Cámaras legislativas, que debía regir en 1916, una partida de tres mil libras para la construcción del edificio de la Morgue utilizando el ofrecimiento del terreno hecho por la Facultad de Medicina. Para dar cima a la obra, se nombró, por suprema resolución de 27 de marzo de 1916, una comisión compuesta del que habla, como catedrático de Medicina legal, del Dr. Juan Antonio Portella, médico de polića de Lima, y del Sr. Enrique Bianchi, arquitecto del Estado, a la que se le dí el encargo de llevar a término la construcción del edificio y dotarlo de todo el material necesario para su buen funcionamiento. No soy yo el llamado a decir como ha cumplido su cometido la Comisión, ni este el momento oportuno para hacerlo: el edifício está a la vista de todos y todos pueden ser jueces al respecto.

Pero lo que si debo mencionar es lo referente a la organización que he conseguido para la Morgue de Lima, que quizás es una de las mas completas, desde el punto de vista de las necesidades que va a satisfacer. La actual Morgue es a la vez una institucion policial y un centro de enseñanza; depende de la Dirección de Policía, del Ministerio de Gobierno, y está también bajo la autoridad de la Facultad de Medicina; su objeto es el reconocimiento y la identificación de los cadáveres, en las condiciones ya conocidas, y la enseñanza práctica de la Medicinalegal; en su personal figuran los dirigentes de la cátedra en la Facultad; y, al local tienen acceso todos los es- 
tudiantes de la asignatura, que en adelante harán el aprendfía práctico de una de las mas importantes disciplinas de la medicina en su aspecto social. Pero hay algo más; el frigorífico de la Morgue va a prestar indiscutibles servicios al Anfiteatro anatómico de la Facultad, proveyendo a la conservación de las piezas anatómicas y a la higienede ese local. $Y$, finalmente el personal médico de la Morgue, conforme a las dispociciones del Reglamento, va a actuar como perito en los casos contenciosos de orden médico legal, en que se le solicite. Es este un primer paso para el establecimiento del peritage médico forense.

Son, pues, múltiples y muy importantes las funciones que va a desempeñar este Instituto, y como entre ellas figura comoprimordial la referencia a los ejercicios prácticos de Medicina legal, que tanto han de influir en la cultura de los futuros profesionales, creo perfectamente justificado el considerar su inauguración como el principio de un nuevo periodo en la existencia de la cátedra de Medicina legal.

La Morgue de Lima, con la organización que se le ha dado, se incorpora en momento oportuno en el rol de las instituciones oficiales del país; cuando la Medicina legal ha realizado grandes progresos; cuando sus enseñanzas se utilizan en casi todas las manifestaciones de la actividad humana; cuando sus conocimientos se difunden por igual a médicos'y a jurisconsultos; cuando se han trasformado por completo las legislaciones civil y penal, cuyos preceptos se informan en el completo conocimiento del hombre sano y enfermo; cuando nuevas legislaciones nacidas para cautelar los inalienables derechos de clerta clase social, verdadera conquista del socialismo contemporáneo, exigen del médico su valioso concurso en múltiples ocasiones muy distintas de aquellas en que actúa sólo para curar o aliviar los procesos morbosos; cuando, en una palabra, la medicina ha adquirido definitivamente su carácter social, sin perder su antiguo rol de trabajar para restablecer el equilibrio perturbado por las enfermedades.

Para que los médicos y los jurtsconsuitos, sean estos últimos legisladores, defensores o jueces, puedan intervenir en la solución de los variados problemas que son del resorte de la medicina social, es indispensable que conozcan con alguna extensión la Medicina legal, clencia de aplicación que aprovecha de los recursos que le suministran todas las ramas de los conocimientos humanos, sea principales o accesorias. Hoy no es suficiente para el médico que quiere desempeñar a conciencia su papel de auxiliar de la administración pública o de la administración de justicia, la masa general de los 


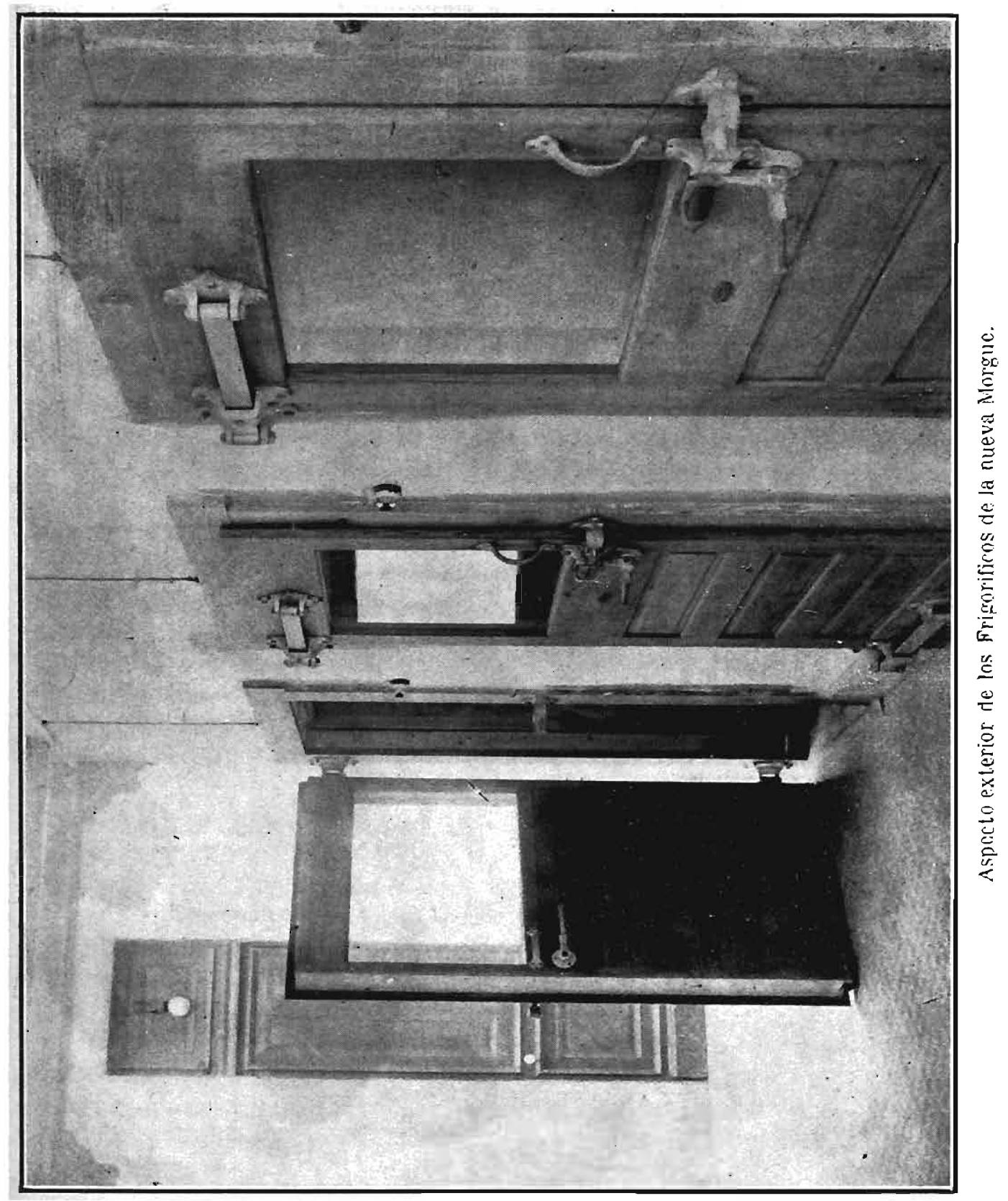


disciplinas médicas: no, es indispensable que conozca con toda perfección las múltiples ramas que se han desprendido del tronco primitivo de la Medicina legal. $Y$ por lo que hace a los jurisconsultos, si en varias ocasiones ante la Sociedad Uni6n Fernandina, en 1887, y ante el Colegio de Abogados, en 1901, he levantado mi voz para hacer en ver la necesidad de que posean conocimientos médico legales, esa exigencia sube hoy de punto en que modificado en el C6digo de procedimientos el modo de apreciar la prueba por peritos, sustituyéndose el criterio legal por el criterio de conciencia, el juez no podrá apreciar la labor del perito médico, si no conoce los canones de la ciencia médico legal, comprendida la psiquiatria.

El perfeccionamiento en los métodcos de la enseñanza de la Medicina legal, que según la opinión de los mas doctos en la materia deben aprovechar por igual los estudiantes de las facultades de medicina y de jurisprudencia, ha sido impuesta por el incesante adelanto de la ciencia y por el no menos incesante ensanche de su campo de acción, del radio de su aplicación a la vida social.

Sería alargar desmesuradamente esta disertación, si hiciera una relación completa de las conquistas realizadasen el terreno de la Medicina legal, durante el último cuarto de siglo: lapso aproximado de tiempo que hace que obtuve el título de adjunto del curso; pero aunque sea en rápida sinopsis indicaré algurias de las que han ađquidrido mayor relieve. Tales sont-el capítulo de la identificaclon trasformado y ensanchado en estos últimos años, transformación a la que han contribuido BERTILLON, el creador de la antropometría y del retrato hablado, GALToN y VuCETICH, a quienes la poIIcía científica debe el infalible procedimiento de la dactiloscopica, el único seguro para la identificación de un sujeto dado, y Oloris AGUILERA, el genial maestro español, que ha perfeccionado la identificación dactiloscopía poniéndola al alcance de cualquier agente de policía;--tratándose de tanatología forense, hay que citar los estudios de ICARD sobre los signos de la muerte real, los de Freire de Carvalho (de Bahía) sobre la fauna de los cadáveres, los de Tamassia sobre las modificaciones microscópicas de los tejidos, los nuevos métodos para diferenclar la muerte rápida de la muerte lenta, sean la docimasia hepática de LACASSAGNE y MARTin y la docimasia suprarrenal de CEvidALII y LEONCINI, y los conocimientos adquiridos sobre la fisiología de las glándulas endocrinicas y sobre las lesiones del manojo de His, que explican muchos casos de muerte súbita cuya causa era antes desconocida; - el capítulo de la traumatología forense, profusamente enriquecido con los estudios sobre las heridas por las modernas armas de fuego, con la aplicación de la ley sobre responsabilidad por los infortunios del trabajo,con el 
nuevo concepto de la fisio-patología de las asfixias, y con los delicadísimos medios de diagnostico que hoy se utilizan en el reconocimientos de estos accidentes:-en los capítulos de la preñez y del infanticidio, mencionaré la utilización para el diagnóstico del embarazo de la reacción de ABDERHALDEN, estudiada también por FERRAi, PESET, CORIN y Welsch, y los estudios de ICARD sobre la prueba de la respiración en el cadáver del recien nacido, en los casos en que es insuficiente el clásico proceder de la docimasia hidrostática:-la prueba microquimica en la investigación toxicologica de las sustancias venenosas, tanto inorgánicas como orgánicas; los estudios de LECHA MARZO sobre el diagnóstico de las manchas de sangre por medio de la formación de los cristales de cloro-hematina y de iodo-hematina, la utilización de los métodos biológicos para diferenciar la sangre humana de la de un animal, entre los que figuran la aplicacion de la anafilaxia (practicada por primera vez entre nosotros por PAJUELo, cuando fué jefe de trabajos prácticos en esta clase) y los estudios hechos por Biffi, en Lima, parahacer el diagnostico de la sangre de dos o mas individuos: método aplicado por GiastiabuRu en un caso práctico en que solicité su valioso consurso:-la aplicación también, de los métodos biológicos y microquímicos para la investigación de las manchas de esperma;-y, finalmente, las valiosas conquistas adquiridas en el campo de la psiquiatría forense y la criminologíal, entre cuyos cultores ocupa sitial de primera!fila el sabio INGENIERos el más genuino representante de la psiquiatrialatinoamericana, uno de los que más han contribuido al perfeccionamiento científico de esta rama de la medicina social.

Cuanto al ensanche en el radio de acción de las aplicaciones dela Medicina legal, será suficiente que mencione lo siguiente:- la completa transformación efectuada en las legislación civil y criminal, transformación lenta, que data ya de varios años, pero que ha culminado en la dación de nuevas codigos cuyas disposiciones armonizan por completo con el estudio biolbgico del hombre. Recuérdese lo que es hoy la legislación sobre el matrimonio, sobre la filiación, sobre los seguros, sobre los variados contratos civiles, sobre el concepto del delito y de la pena, sobre la pena condicional, sobre la sentencia indeterminada, sobre la represión de la criminalidad infantil, de la trata de blanca, y tantas otras cuestiones de orden penal, y se comprenderá con facilidad que es imposible que el médico o el juez puedan solucionarlas si desconocen las modernas adquisiciones de la ciencia;- - la nueva legislación del trabajo, en todas sus variadas orientaciones, capítulo nuevo y de trascendental importancia de la ciencia jurídica, creado con los materiales suministra- 
dos por la Medicina legal y sus ciencias auxiliares, y en cuya aplicación desempeñan papel preponderante los cultores de la medicina forense:-las innovaciones introducidas en la función policial, que de empírica como lo ha sido durante tantos años se ha trasformado en policía científica, lo que obliga a cambio radical en sus medios de investigación y de acción, a selección detenida de su personal, que hoy debe estar suficientemente capacitado para comprender el espíritu de la ley y las circunstancias de orden biologico que intervienen en las infracciones, en las simples faltas de policía y en la comisión de los delitos; - y, la protección a la niñez desvalida a todos los necesitados, que hoy constituye función importantísima de los poderes públicos.

Pero para que puedan perfeccionarse los métodos en la enseñanza de la Medicina legal, es necesario que los poderes legislativo y ejecutivo proporcionen los elementos de todo género que se requieren para ello, y que los organicen en forma tal que todos los que tienen que intervenir en la confección de las leyes, en su interpretación y en su aplicación, cualesquiera que sea la gerarquía de la funcion que desempeñen, puedan adquirir los conocimientos indispensables tanto de las disciplinas médicas como de las jurídicas para proceder con sujección a las dispociciones de la ley, a la estabilidad del orden social y a la seguridad del individuo y de la sociedad. Son los poderes constituídos los que crean las teyes, en vista de las necesidades de la colectividad, y son ellos los que deben proveer a su oportuna y justa aplicación. Como lo dice con mucha justicia el Prof. H. ZANGGER, de Zurich:-ues evidente, a priori, que la aplicación de las leyes no puede ser justa, sino con la condición de que todos los funcionarios que tienen que apreciar los hechos importantes en las cuestiones jurídicas, se hallen en idéntico nivel científico. Y hoy en gran número de cuestiones, las funciones de comprobación las ejercen exclusivamente los médicos y no pueden ser hechas sino por los médicos».

$Y$ esta observación del profesor $Z_{A N G G E R}$ es aplicable en nuestro medio en el que como se sabe falta la enseñanza de la Medicina legal para los jurisconsultos, y nada se ha hecho aún de provecho para reformar los primeros trámites del procedimiento criminal y para dotar a la policía de personal preparado con sujección a los preceptọs de la policía científica.

Hay algo mas, los poderes del Estado no solo tienen obligación de preocuparse en estos importantes asuntos, que se rozan con la buena administracion de justicia y con la marcha harmonica de la colectividad sino que en caso de omision gravita sobre ellos sería responsabilidad. Las graves incorrecciones de la policía, la deficienca 
de las operaciones médico legales, los graves errores del poder judicial, etc., que desgraciadamente se contemplan a diario ¿a que se deben?: a insuficiencia de conocimientos medico forenses, en los funcionarios correspondientes. El mismo Prof. ZaNGGER, dice a este respecto lo siguiente:- «Si los gobiernos no se toman el trabajo de hacer que aprendan estos hechos, los procedimientos científicos de la medicina forense, todas las personas que han de desempeñar funciones oficiales, y si estos funcionarios, jurisconsultos y médicos, no conocen los medios de accion de los unos y de los otros, los momentos en que deben aunar su labor, para completarla y perfeccionarla, entonces fatalmente, (lo repito fatalmente) las leyes no sirven sino para que las usufructen los intereses personales, con detrimento del espíritu y de la finalidad de la ley».

Es apoyándome en estas oonsideraciones que he dicho, y lo repito, que esta repartición inicia sus labores en el momento oportuno. Con la voluntad decidida del ilustre mandatario que gobierna el país, he podido conseguir que la Morgue tenga no sólo finalidad policial, sino que también sea centro de ilustración técnica, tanto para los escolares como para todos los estudiosos que quieran orientarse en las bellas y proficias disciplinas de la medicina forense $Y$ desde este punto de vista, el gobierno del Dr. Pardo ha cumplido debidamente su deber, contribuyendo a la más amplia difusión de estos conocimientos especiales.

Pero lo hecho hasta hoy no es sino el principio de la magna obra que precisa llevar a cumplido término. Mucho se ha avanzado con la instalación de esta dependencia: se mejorará bastante la instruccion técnica de los alumnos de la Facultad de Medicina, puesto que hay notable diferencia entre los procederes antiguos y el método objetivo que en adelante servirá para la enseñanza; pero los escolares de San Fernando no son los únicos que necesitan conocer los secretos de la Medicina forense, hay muchos otros entre los intelectuales y hasta entre los modestos - pero no por ello menos meritorios-servidores de la Nación, para quienes es condición indispensable estar suficientemente capacitados para poder llenar cumplidamente su deber.

El remedio es muy sencillo, y mas que todo de fácil e inmediata realización, convertir esta repartición en un verdadero Instituto de Medicina Legal, de Medicina Forense. El personal está listø: lo constituyen los catedráticos de Química, de Psiquiatria y de Medícina legal de la Facultad de Medicina, uno de los catedráticos de Derecho penal de la Facultad de Jurisprudencia, y los jefes de trabajos prácticos y ayudantes de las resespectivas clases de la $\mathrm{Fa}$ cultad de Medicina; este local, con lijeras innovaciones quedaría 
perfectamente adaptado para el objeto; los gastos que habría que hacer, no representan una suma fabulosa; no sería muy crecida la partida necesaria para su sostenimiento; $y$, como compensación de todo esto se habría un dado un gran paso en la marcha del progreso científico, se tendría muy pronto personal preparado para las labores de la policía científica para el buen desempeño de la augusta función judicial y para la práctica del peritage médico legal. Aunemos nuestros esfuerzos, los dirigentes de las facultades universitarias de jurisprudencia y medicina, los personeros de la prensa profesional, los cultores de la medicina social y todos los que nos interesamos en estas trascendentales cuestiones, y formulemos nuestro pedido al Sr. Presidente de la República, que estoy seguro que será favorablemente atendido y que muy pronto tendremos la satisfacción de ver realizados nuestros anhelos: con lo que no sblo realizaremos obra provechosa, sino también patrítica, pues será Lima la primera capital de Sud América que tenga un Instituto de Medicina legal.

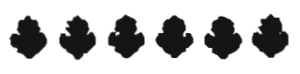

